\title{
Erratum: Thickness and Structure of Adsorbed Water Layer and Effects on Adhesion and Friction at Nanoasperity Contact. Colloids Interfaces 2019, 3, 55.
}

\section{Colloids and Interfaces Editorial Office}

MDPI, St. Alban-Anlage 66, 4052 Basel, Switzerland; Colloids@mdpi.com

The Editorial Office of Colloids and Interfaces would like to make the following correction to the paper by Xiao, C. et al. (2020) [1]:

Figure 22 in the main text was misprinted in the published version. The correct figure should be:

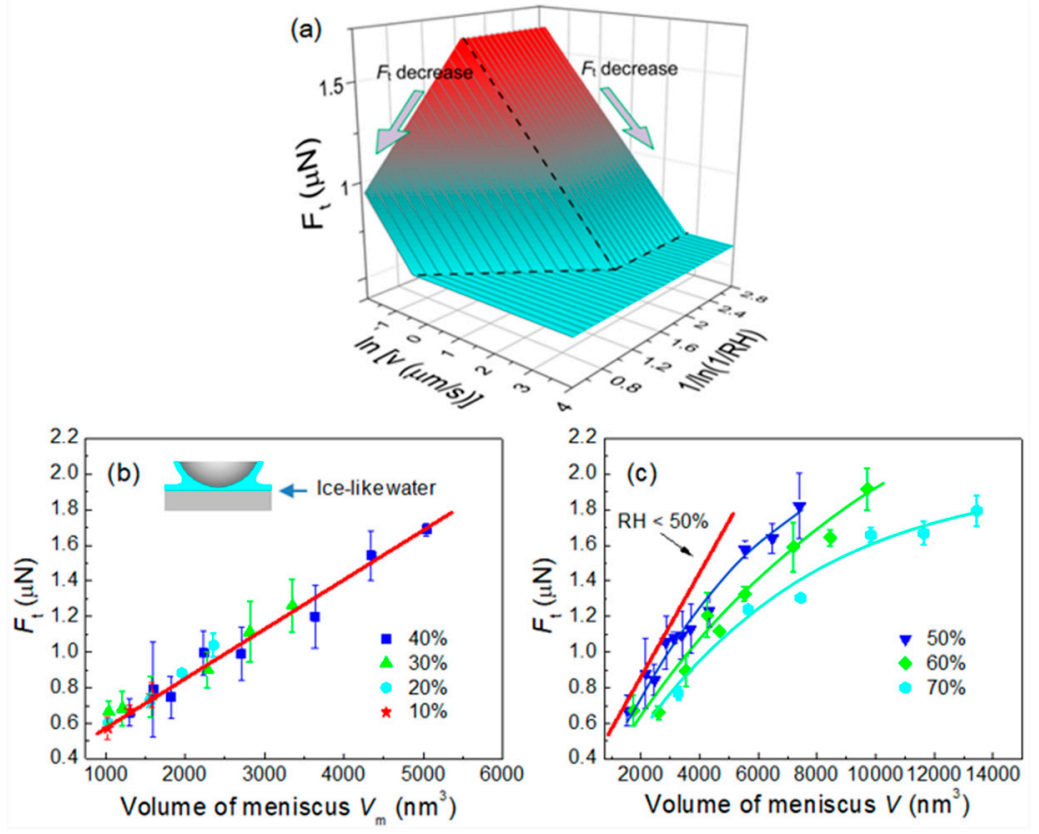

The manuscript will be updated and the original will remain online on the article webpage. We would like to apologize for any inconvenience caused.

\section{Reference}

1. Xiao, C.; Shi, P.; Yan, W.; Chen, L.; Qian, L.; Kim, S.H. Thickness and Structure of Adsorbed Water Layer and Effects on Adhesion and Friction at Nanoasperity Contact. Colloids Interfaces 2019, 3, 55. [CrossRef]

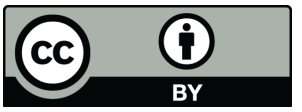

(C) 2020 by the author. Licensee MDPI, Basel, Switzerland. This article is an open access article distributed under the terms and conditions of the Creative Commons Attribution (CC BY) license (http://creativecommons.org/licenses/by/4.0/). 